\title{
Parâmetros para a eficácia horizontal dos direitos fundamentais
}

\section{Parameters for the horizontal effect of constitutional rights}

\author{
Rafael de Souza Borelli'; Francisco Emílio Baleotti²
}

\section{Resumo}

Os princípios jurídicos (espécies do gênero norma jurídica), seguindo a teoria de Alexy, são mandamentos de otimização do ordenamento jurídico. Isto é de interesse, já que os direitos fundamentais têm, em regra, a natureza de princípios. Neste diapasão, a doutrina passou a discutir acerca da vinculação dos particulares a direitos fundamentais. No âmbito alemão, foram estudadas, principalmente, as teorias da eficácia imediata e mediata, enquanto que, no âmbito estadunidense, discutiu-se acerca da state action. Neste século, estas teorias passaram a ser estudadas no Brasil, com produção científica acerca do tema. Nesta senda, o presente trabalho buscará dialogar com estas teorias, com fito de se chegar, enfim, a uma sistematização lógica satisfatória, com criação de parâmetros, tendo em vista a existência de prévia mediação legislativa, a essencialidade da relação jurídica (econômica ou existencial) ou sua verticalidade.

Palavras-chave: Teoria dos princípios. Direitos fundamentais. Vinculação dos particulares. Sistematização.

\begin{abstract}
The legal principles (species of rule of law) on the theory Robert Alex optimization commandments are legal. This is of interest, since fundamental rights are, as a rule, the nature of principles. In this vein, the doctrine came to discuss about the linking of individuals to fundamental rights. Under German, were studied mainly theories mediate and immediate effectiveness, whereas under United States, it was discussed about the state action. In this century, these theories began to be studied in Brazil, with scientific literature on the subject. In this vein, this paper aims to engage with these theories, with aim of reaching finally a logical systematization satisfactory with creating parameters in view of the existence of prior legislative mediation the essentiality of the legal relationship (economic or existential) or its verticality.
\end{abstract}

Keywords: Theory principles. Fundamental rights. Linking individuals. Systematization.

\section{Introdução}

O presente trabalho buscará, de maneira não exauriente, elucidar a problemática da eficácia horizontal dos direitos fundamentais (vinculação dos particulares a direitos fundamentais), com análise das posições tanto jurisprudenciais como doutrinárias, verificando qual atenderia melhor às especificidades de nosso país, com base nos princípios vigentes na Constituição Federal.

\footnotetext{
${ }^{1}$ Bacharel em Direito pela Universidade Estadual de Londrina; Advogado;Pós-graduado em Direito pela Fundação Escola do Ministério Público do Paraná - FEMPAR; Mestrando em Direito Negocial pela Universidade Estadual de Londrina. Email: rafael.borelli.uel@gmail.com

${ }^{2}$ Mestre em Direito das Relações Sociais pela Universidade Estadual de Londrina; Doutor em Direito das Relações Sociais pela Pontifícia Universidade Católica de São Paulo; professor permanente do Programa de Mestrado em Direito Negocial da Universidade Estadual de Londrina. Email: febaleotti@gmail.com.
} 
Para realizar o presente exame, estruturouse o trabalho de forma simples. Iniciar-se-á o estudo com análise acerca da teoria dos princípios jurídicos, com exame mais aprofundado da visão do estudioso alemão, Robert Alexy, acerca da teoria dos princípios, a qual contrasta com a tradição jurídica brasileira, que descreve os princípios, tanto como 'mandamentos nucleares do sistema', quanto como 'vetores interpretativos.

Em seguida, anotar-se-á acerca dos aspectos históricos dos direitos fundamentais, que inicialmente serviram como meio de proteção dos particulares contra o Estado absoluto e que, posteriormente, passaram a significar a obrigação do Estado de disponibilizar aos seus súditos certos serviços, como a educação, saúde, entre outros. Mais à frente, já no seio da sociedade de massa, percebeu-se que os direitos fundamentais ainda se mostravam insuficientes para as demandas de então, motivo que influenciou a positivação dos direitos ao meio ambiente equilibrado e outros de natureza supraindividual. Este é o estudo das chamadas 'dimensões' dos direitos fundamentais.

Desta ideia de evolução histórica dos direitos fundamentais, extrai-se a noção do que seja a eficácia horizontal dos direitos fundamentais, vez que, no seio da sociedade de massas, os particulares passaram também, a violar os direitos fundamentais uns dos outros. Realizada esta incursão, buscar-se-á, então, perquirir acerca de possíveis fundamentações no direito positivo brasileiro que autorizem a vinculação dos particulares a direitos fundamentais.

Estabelecida a premissa no direito positivo nacional, iniciar-se-á estudo das principais teorias da eficácia horizontal dos direitos fundamentais, a saber: da eficácia mediata, da eficácia imediata, da imputação do Estado, e a teoria de Robert Alexy.

Já nas proximidades do fim da exposição, buscar-se-ão possíveis conclusões para a questão apresentada, com releitura das obras nacionais de maior fôlego acerca da vinculação dos particulares a direitos fundamentais.
Por fim, adotar-se-á uma posição acerca do tema, demonstrando-se o porquê de tal postura, sendo o discurso terminado com uma proposta de sistematização do conteúdo apresentado.

Neste sentido, justifica-se a pesquisa ora apresentada, por tratar-se de tema relativamente novo no seio da doutrina constitucional brasileira, sendo de maior importância, ainda, por se buscar sistematizar os institutos expostos, com fim de fomentar discussões e debates na academia.

\section{Apontamentos Temático-Metodológicos e Terminológicos}

Por tratar-se de tão interessante e extenso tema, é necessária uma delimitação do que se irá abordar no presente artigo.

Como exposto acima, a pesquisa limitar-se-á a realizar um estudo não exauriente acerca da teoria dos princípios, vez que aqui se sustenta que os direitos fundamentais têm natureza principiológica. Após transitar por estes conceitos, a pesquisa direcionar-se-á às teorias da vinculação dos particulares a direitos fundamentais, com verificação da argumentação favorável e contrária a cada uma, para, ao final, realizar-se uma singela tentativa de sistematização do conhecimento antes exposto.

Tudo isto será feito com base no método hipotético-dedutivo.

Ademais, como será salientado mais à frente, utilizar-se-á aqui, prioritariamente, os conceitos de Robert Alexy acerca dos princípios e dos direitos fundamentais.

Ademais, em relação às nomenclaturas "efeito horizontal", "aplicabilidade horizontal", "eficácia horizontal" e "vinculação dos particulares a direitos fundamentais", embora exista na doutrina discussão sobre o correto uso de cada uma, para o presente trabalho, pela exiguidade do espaço em solucionar tão sutil problema, os termos serão utilizados como sinônimos. 


\section{Considerações Sobre os Princípios Jurídicos}

Antes de se adentrar na problemática do presente artigo, é importante uma visualização acerca das visões dos juristas pretéritos acerca do conteúdo e alcance dos princípios jurídicos. Por questões de espaço, não serão abordados alguns dos aspectos históricos dos princípios jurídicos.

Inicia-se o estudo com a definição de princípios destacada por Crisafulli, o qual foi o primeiro jurista, efetivamente, a entender os princípios como uma norma jurídica, dotada de coercitividade. O jurista italiano, citado por Bonavides, dizia, já em 1952, o seguinte:

Princípio é, com efeito, toda norma jurídica, enquanto
considerada como determinante de uma ou de muitas
outras subordinadas, que apressupõem, desenvolvendo
e especificando ulteriormente o preceito em
direções mais particulares (menos gerais), das quais
determinam, e, portanto, resumem, potencialmente,
o conteúdo: sejam, pois, efetivamente postas,
sejam, ao contrário, apenas dedutíveis do respectivo
princípio geral que as contém (CRISAFULLI apud
BONAVIDES, 2008, p. 257).

Para o jurista italiano, os princípios exerciam duplo papel: o papel normativo e um papel interpretativo, ou seja, sua eficácia não se esvaía, quando não eram diretamente aplicados, visto que poderiam ser utilizados como cânones interpretativos.

Após a divulgação das ideias de Crisafulli, a noção de que os princípios eram dotados de normatividade passou a se espalhar pelo universo jurídico, possibilitando os grandes debates atuais acerca dos princípio (apud SILVA, 2003, p. 145).

\section{A Dicotomia Regras X Princípios}

Mesmo após a salutar contribuição de Crisafulli, multiplicaram-se os conceitos de princípios, sendo alguns muito similares e outros nem tanto. Neste ponto, pode-se salientar a investigação do jurista argentino Riccardo Guastini que dividiu em seis os conceitos hegemônicos de princípio:

1) princípios são normas dotadas de alto grau de generalidade ${ }^{3}$;

2) princípios são normas altamente indeterminadas, as quais, sem concretização interpretativa, são inaplicáveis;

3) princípios são normas de caráter programático;

4) princípios são normas com alta posição hierárquica no ordenamento;

5) princípios são normas que desempenham função fundamental nos sistemas (ramos) jurídicos individualmente observados (direito processual, direito penal, direito administrativo, etc) $;{ }^{4}$

6) princípios são normas dirigidas aos aplicadores do direito, atuando como 'cânones' interpretativos $^{5}$ (GOMES, 2010; GUASTINI, 2006).

Estes são os seis conceitos de princípio mais comumente utilizados, segundo a obra de Guastini. Nesta senda, é imperioso salientar que muitas vezes, seja na academia, seja na aplicação prática, os conceitos acabam sendo homogeneizados, acarretando o que foi chamado, por Virgilio Afonso da Silva (2005b), de 'sincretismo metodológico'.

Feito este interlúdio, passa-se a estudar a visão do jurista estadunidense, Ronald Dworkin, acerca do tema, sendo sua contribuição importantíssima até hoje.

\section{A Visão de Dworkin}

Com a difusão do conceito de princípios como normas, houve uma espécie de "Virada de Copérnico" no âmbito da Teoria do Direito. Esta "Virada" foi capitaneada pelas ideias do americano

\footnotetext{
${ }^{3}$ Soares (2005) tem posição similar.

${ }^{4}$ Este conceito parece similar ao que definem Grinover, Cintra e Dinamarco (2011, p. 56-59) como princípios gerais.

${ }^{5}$ Esta definição assemelha-se à de Celso Antônio Bandeira de Mello (2002, p. 545).
} 
professor da Universidade de Oxford, Ronald Dworkin (2002). O jurista estadunidense criou a dicotomia regras $\mathrm{X}$ princípios, para demonstrar que um sistema "puro" de regras seria incapaz de resolver os chamados "casos difíceis". Dworkin, buscando rebater as teorias de Hart, seu antecessor na cadeira de Teoria do Direito em Oxford, apontou que regras e princípios eram espécies do gênero normas jurídicas, diferenciando-as, ao apontar que as regras seriam aplicadas de forma tudo ou nada (all or nothing), enquanto os princípios deveriam ser conjugados com outros fundamentos, derivados de outros princípios. Para Dworkin, os princípios deveriam ser analisados sob a ótica de seu peso relativo, dentro de cada caso concreto (DWORKIN, 2002).

Ou seja, no caso de incidência da hipótese fática disposta numa regra, aquela regra deverá ser aplicada. Se não incidir a hipótese, a regra permanece 'inerte'. Um exemplo singelo de regra e sua vocação 'tudo ou nada': "O atraso à sala de aula acarretará a perda de meio ponto na média final”. No caso de atraso, a sanção deverá ser aplicada inteiramente, sendo que, na não incidência, a regra não é aplicada. A sutileza argumentativa de Dworkin erige-se na impossibilidade de modulação dos efeitos e contradições das regras. Quando há uma regra expressa, não há possibilidade de elastificação da disposição (o professor não poderia, no caso de um atraso ínfimo, aplicar sanção de um décimo na média final) (DWORKIN, 2002).

O termo "tudo ou nada", também, tem relação com regras conflitantes entre si. Um exemplo é a regra constitucional de irretroatividade da lei penal, a qual prevê, excepcionalmente, a retroatividade de lei penal benéfica ao réu. Ou seja, a própria regra já prevê uma exceção à sua aplicação, que, neste caso, será a aplicação completa da regra excepcional. Neste esteio, a verificação da validade ou não de uma regra depende de uma análise de validade, em outras palavras, se há cláusula de exceção, seja pelo lado temporal (lei posterior derroga lei anterior) ou pelo lado da especialidade (lei especial derroga lei geral).
No que tange aos princípios, Dworkin (2002) visualiza a dimensão do peso, em outras palavras: tem prevalência aquele princípio que for, para o caso concreto, mais importante, ou, metaforicamente, aquele que tiver maior peso. Importante é visualizar que o princípio que não tiver prevalência não deixa de valer ou de pertencer ao ordenamento jurídico. Ele apenas não terá tido peso suficiente para ser decisivo naquele caso concreto. Em outros casos, porém, a situação pode inverter-se. Diferentemente do que foi exposto acerca das regras dworkinianas, os princípios não são expulsos do ordenamento por outros (SILVA, V., 2003).

Verifica-se, portanto, que chegava-se, então, (meados dos anos 1970) a uma sistematização do que seriam princípios. A seguir, observar-se-á a contribuição de Robert Alexy às bases criadas por Dworkin.

\section{A Teoria de Robert Alexy}

A teoria de Robert Alexy, ao olho desatento, pode parecer similar a de Dworkin, já que, também, aponta a existência, dentro dos ordenamentos jurídicos, de um complexo normativo composto de regras e princípios, sendo as normas o gênero do qual aqueles (regras e princípios) são espécies (ALEXY, 2008, p. 86).

Contudo, a famosa lição de Alexy dispõe que os princípios são "mandamentos de otimização do ordenamento jurídico, normas que obrigam que algo seja realizado na maior medida possível, de acordo com as possibilidades fáticas e jurídicas." Esta lição pode parecer genérica, mas é deveras científica. Para Alexy, as condições sob as quais um princípio tem precedência em face de outro constituem o suporte fático de uma regra que expressa a consequência jurídica do princípio que tem precedência. Ou seja, para o jurista germânico, sempre que, no caso concreto, após o devido sopesamento, um princípio der precedência a outro, criar-se-á uma regra para aquele caso individual (ALEXY, 2008, p. 99). 
Aprofunda-se: para Alexy, as regras estabelecem deveres definitivos (à semelhança do 'tudo ou nada' de Dworkin) e os princípios estabelecem deveres prima facie. No âmbito dos princípios, é que erige-se a diferença entre o pensamento do autor alemão e do estadunidense. No caso de Dworkin, o conflito entre princípios (apesar de não ocasionar a derrogação do princípio 'perdedor') significa que um deles não será aplicado ao caso concreto. Já, para Robert Alexy, o conflito entre princípios pode significar a aplicação parcial de cada princípio ou, também, na aplicação total de um dos princípios, com toda a argumentação pautada pela aplicação da regra da proporcionalidade (BUSTAMANTE, 2010). ${ }^{6}$

Nisto, está a maior cientificidade da ideia de Alexy, visto que proporciona uma gama maior de soluções jurídicas ao julgador, sempre tendo em vista a otimização na aplicação dos direitos fundamentais.

\section{Considerações Iniciais sobre os Direitos Fundamentais}

É notória que a posição histórica dos direitos fundamentais foi sempre de defesa dos cidadãos em face do Estado. Inicialmente, os direitos fundamentais foram o produto peculiar do pensamento burguês do final do século XVIII (BONAVIDES, 2006, p. 563). Seus primeiros reflexos no Direito Positivo foram a Declaração de Direitos do Bom Povo de Virginia (1776), a Declaração Universal de Direitos do Homem e do Cidadão (1789), entre outras. Os direitos, então, reconhecidos como fundamentais eram tipicamente direitos de defesa do indivíduo frente ao Estado, direitos do indivíduo de que o Estado abstenha-se de certas condutas, como, por exemplo, o direito do cidadão à integridade física, à propriedade e à liberdade. Estes direitos ficaram consagrados na doutrina como os direitos fundamentais de primeira dimensão ${ }^{7}$ (SARLET, 2009, p. 45-54; VIEIRA, 2006, p. 38).

Ou seja, ao tempo do triunfo do liberalismo clássico, o Estado era visto como um 'mal necessário' e, por isso, devia ter seus poderes estritamente definidos, limitados e controlados, através de uma Constituição. Não é à toa que o Artigo 16 da Declaração dos Direitos do Homem e do Cidadão tinha a seguinte redação: A sociedade em que não esteja assegurada a garantia dos direitos nem estabelecida a separação dos poderes não tem Constituição (apud FERREIRA FILHO; GRINOVER; FERRAZ, 1978, grifo nosso).

Com o advento da Revolução Industrial e o impacto o qual esta causou nos meios de produção e circulação das riquezas, ocorreram grandes mudanças na dinâmica social. Apenas a existência dos direitos de defesa dos particulares contra o Estado não garantia aos cidadãos uma existência sadia, vez que, apesar das Constituições preverem os direitos de primeira dimensão aos indivíduos, as mesmas não propiciavam a estes os meios para a consecução daqueles direitos (SILVA, 2004, p. 159-160). Por isto, a nota distintiva daqueles novos direitos fundamentais (direitos de segunda dimensão) foi a sua dimensão positiva, a garantia de uma atividade estatal. Exemplos dos direitos que passaram a ser positivados são os direitos à educação, saúde, trabalho, moradia, alimentação, cultura, previdência e assistência sociais, entre outros. Apesar destes direitos terem sido positivados em meados do século XIX, foi apenas no século XX que os mesmos passaram a ter maior efetividade, principalmente no momento em que as

\footnotetext{
${ }^{6}$ Para mais detalhes acerca da aplicação da regra da proporcionalidade, conferir Silva (2002); Borelli (2011). Já no que diz respeito à honestidade de argumentação presente na aplicação da regra da proporcionalidade alexyana (a qual tem relação com o pensamento de Habermas). Conferir em Alexy (2001).

7 De relevo assinalar que existem fundadas críticas ao termo "gerações" de direitos fundamentais, motivada pela razão desta 'expressão' causar uma impressão da substituição gradativa de uma geração por outra, razão pela qual utilizou-se, aqui, da ‘expressão' dimensões, ao invés da ‘expressão’ gerações'. A respeito desta discussão, Marmelstein (2008) e Sarlet (2009).
} 
Constituições (dentre as quais, a brasileira) passaram a formular o preceito da aplicabilidade imediata dos direitos fundamentais (SARLET, 2009, p. 55-56; BONAVIDES, 2006, p. 564).

Já no último terço do século XX, derivados de novas comoções sociais originadas das evoluções tecnológicas, e das, cada vez mais rápidas, transformações sociais, surgiram os direitos de solidariedade e fraternidade, também, chamados de direitos de terceira dimensão. Estes se caracterizam por sua natureza difusa ou coletiva, contudo, a doutrina diverge em relação aos direitos consagrados nesta terceira dimensão, sendo o direito ao meio ambiente ecologicamente equilibrado o mais lembrado (SARLET, 2009, p. 56-58; BONAVIDES, 2006, p. 523).

Há certas discussões no interior da doutrina constitucional acerca da existência de uma quarta e/ou quinta dimensão dos direitos fundamentais, contudo, por questões de espaço e temática, não se adentrará nesta discussão no presente trabalho ${ }^{8}$.

No contexto apresentado, percebe-se, seja qual for o critério ou classificação adotado, que os direitos fundamentais historicamente vêm ampliando de maneira robusta o seu rol e o seu significado.

Prosseguindo nesta linha, verificando-se a progressão histórico-positiva realizada pelos direitos fundamentais, passa a ser crível a afirmação de que os direitos fundamentais, para que atinjam um grau aceitável de promoção de justiça social, não podem ser oponíveis somente perante o Estado, mas sim, também, perante os outros particulares (ALEXY, 2008, p. 528).

Aliás, é de salientar que, já de muito tempo, a direção da sociedade não vem cabendo mais ao Estado, concentrando-se em outras forças, como as corporações e os grupos de pressão, o que, por óbvio, impõe uma nova visão acerca da eficácia dos direitos fundamentais (CASTRO, 2008, p. 133152).

Sarmento aponta, outrossim, que a plena normatividade dos princípios e sua consequente projeção no ramo do direito privado é uma maneira de humanizar as relações privadas, submetendo-as ao crivo da Constituição, a qual tem como norte promover e proteger a dignidade da pessoa humana (SARMENTO, 2003, p. 272-297).

Dito isto, analisar-se-ão quais seriam os marcos positivos e teóricos para a fundamentação da oponibilidade perante particulares dos direitos fundamentais.

\section{As Teorias da Vinculação dos Particulares aos Direitos Fundamentais no Direito Comparado e no Brasileiro}

Como muitas das teorias do direito constitucional, a teoria da eficácia horizontal dos direitos fundamentais, também chamada de vinculação dos particulares a direitos fundamentais, teve seu início na Alemanha, em meados dos anos 1950 (STEINMETZ, 2005, p. 11-53). Canaris (2003, p. 223-244) aponta o início da discussão, na doutrina alemã, como sendo o emblemático caso Luth ${ }^{9}$.

Após a prolação da decisão do Caso Luth, a doutrina alemã passou a tentar sistematizar a ideia da aplicabilidade dos direitos fundamentais frente aos particulares.

As principais teorias cunhadas são: teoria da eficácia mediata, teoria da eficácia imediata, teoria da imputação do Estado e a teoria integradora de

${ }^{8}$ Sobre o tema, conferir: Bobbio (2004); Bonavides (2008); Silva (2003); Sarlet (2009).

${ }^{9} \mathrm{O}$ caso tratava de um particular (Luth) que iniciara uma campanha, no ano de 1950, contra um filme, alegando que o diretor daquela película havia produzido filmes antissemitas no período do nazismo. Inicialmente, o protesto foi julgado ilegal, contudo, a Corte Constitucional o entendeu lícito, dizendo a liberdade de expressão, sendo direito fundamental, influía também no Direito Civil, cunhando a expressão, usada amplamente atualmente, de 'efeito irradiante' dos direitos fundamentais. Importante salientar, ademais, que a aplicação de direitos fundamentais entre particulares, no caso Luth, foi feita pela Corte Constitucional alemã, através da interpretação da cláusula geral dos ‘bons costumes', vez que a produtora cinematográfica alegara que Luth agira contra os bons costumes ao incitar o boicote. Para maiores detalhes, Steinmetz (2004; p. 146) e Silva (2004, p. 97). 
Robert Alexy (STEINMETZ, 2004, p. 137). Elas serão vistas a seguir.

\section{Teoria da eficácia mediata}

Esta teoria foi criada e defendida pelo alemão Günther Dürig, sendo, ultimamente, acolhida pela jurisprudência da corte constitucional alemã (NEUNER, 2003; PEREIRA, 2003).

Barroso (2009, p. 51-92) explica a teoria da eficácia mediata como sendo aquela em que o legislador realiza, a priori, (através de norma infraconstitucional), uma restrição à autonomia da vontade, somente quando há atuação judicial em segundo plano. Steinmetz (2005, p. 21) aprofunda mais o ensinamento de Barroso, dizendo que, no caso de inexistência de regulação legislativa acerca do caso, cabe ao Magistrado, perante o caso concreto, na invocação das cláusulas gerais ${ }^{10}$, aplicá-las em conformidade com os valores previstos no texto constitucional.

$\mathrm{Na}$ doutrina alemã, havia grande preocupação que, caso se entendesse pela aplicação direta dos direitos fundamentais às relações privadas, ocorressem diversos problemas, como um esvaziamento do direito civil, o qual passaria a ser preenchido pelo constitucional e mais, que inviabilizaria a autonomia privada, tão importante para individualização do cidadão numa sociedade de massas. Tais críticas serão analisadas mais à frente.

\section{Teoria da eficácia imediata}

Já para os que postulam a eficácia imediata, há o entendimento que as normas fundamentais operam eficazmente entre particulares, independente de regulação do legislador e, na grande maioria das vezes, são aplicadas pelo julgador (SARLET, 2004, p. 120). Esta tese foi inicialmente sustentada por
Hans Nipperdey, então, presidente da Corte Federal do Trabalho alemã, em meados dos anos 50.

No Brasil, o Supremo Tribunal Federal, intérprete máximo da Constituição, vem se posicionando, nas poucas vezes em que foi provocado acerca da matéria, como favorável à teoria da aplicação imediata (MARETTI, 2010, p. 66-80). O posicionamento do Supremo deu-se no bojo do Recurso Extraordinário 201.819/RJ, em decisão da Segunda Turma, por maioria de votos. O caso versava, em síntese, sobre uma associação que excluíra de seus quadros um associado, sem lhe proporcionar direito à defesa adequada.

Luis Roberto Barroso (2009, p. 51-92) entende que, na atual situação brasileira, esta seria a melhor teoria a ser aplicada, levando-se em conta os seguintes elementos: i) desigualdade entre as partes; ii) falta de razoabilidade dos outros critérios; iii) preferência dos valores existenciais sobre os patrimoniais; iv) risco para a dignidade humana. Do mesmo entendimento comunga Ingo W. Sarlet, apontando, inclusive, que a eficácia imediata serviria para vincular os particulares aos direitos sociais (SARLET, 2009, p. 587-614).

Steinmetz (2004, p. 169) salienta que esta teoria possui diversos matizes. O matiz forte seria o que foi originalmente criado por Nipperdey, em que os direitos fundamentais operam geral, plena e indiferenciadamente em relação aos particulares. Sob a ótica do matiz fraco, haverá vinculação dos particulares a direitos fundamentais, especialmente na hipótese de grande desigualdade fática entre os contratantes (posição de Ubillos, 2003). Por último, o matiz intermediário situa-se no meio-termo entre os outros (posição de Canotilho e Sarlet) ${ }^{11}$.

As objeções a esta teoria (e seus matizes) serão vistas à frente.

\footnotetext{
${ }^{10}$ As cláusulas gerais são normas que não prescrevem uma conduta específica, mas simplesmente definem valores e parâmetros hermenêuticos, servindo assim como um topos interpretativo, oferecendo ao intérprete os critérios axiológicos e os limites para a aplicação das demais disposições normativas (TEPEDINO, 2002. p. 19).

${ }^{11}$ Para maior aprofundamento Steinmetz (2004, p. 169).
} 


\section{Teorias da imputação estatal e da State Action}

Outra das teorias aplicáveis à vinculação dos particulares a direitos fundamentais é a teoria da imputação do Estado, a qual prescreve que toda e qualquer vinculação de direitos fundamentais nas relações particulares é imputável ao Estado, que deveria ter agido para evitar aquela violação (SARMENTO, 2004a, p. 263).

A teoria foi cunhada por Jürgen Schwabe, autor teutônico. Esta teoria não reverberou bem na doutrina alemã e nem na brasileira, recebendo críticas de Alexy (2008, p. 531), Sarmento (2004a, p. 263), Steinmetz (2004, p. 178), Braga (2008, p. 137), entre outros. A crítica é pertinente, uma vez que imputar toda violação de direitos fundamentais realizada por particulares ao Estado acarretaria um aumento desmesurado da influência estatal nas relações privadas, como, também, seria 'esvaziador' à liberdade individual de contratar, sendo que, de outro lado, tornaria praticamente impossível a responsabilização civil dos particulares violadores de direitos fundamentais.

De outro lado, a teoria da state action foi a alternativa estadunidense à teoria da imputação estatal, sendo, em verdade, uma evolução em relação a esta última. É de se salientar que a teoria constitucional norte-americana entendeu, historicamente, que os civil rights vinculavam somente o Estado (PEREIRA, 2003). Contudo, a Supreme Court, de maneira engenhosa, passou a entender que, no caso de um particular exercer uma função tipicamente deEstado, ou se, no caso concreto, for possível implicar o Estado a esta conduta ilícita pelo particular, os direitos fundamentais atuarão em benefício do lesado (UBILLOS, 2003, p. 299, 338; SARMENTO, 2004b, p. 193-284).

As objeções a estas teorias serão vistas à frente.

A teoria de Alexy

A última das teorias aqui abordadas, esposada por Robert Alexy, retira de cada uma das outras suas premissas, criando uma sistematização lógica. $\mathrm{O}$ autor, em argumentação deveras convincente, aponta que a eficácia horizontal dos direitos fundamentais dá-se em três níveis: o do dever estatal, o dos direitos em face do Estado e o das relações privadas (ALEXY, 2008, p. 533). Para ele, a teoria da eficácia mediata situa-se no nível do dever estatal, vez que as normas fundamentais devem servir como baliza ao legislador. Já a teoria de Schwabe situa-se no nível da proteção do particular em face do Estado, enquanto a teoria da eficácia imediata encontra-se no nível das relações privadas.

Ou seja, Alexy compreende as três teorias como válidas. Contudo, ele aponta que, ultimamente, mesmo com a aplicação das diversas teorias, existirá uma eficácia imediata, sendo que o grau da eficácia dependerá do caso concreto e da argumentação jurídica utilizada (ALEXY, 2008, p. 540).

São estas, portanto, as principais teorias, no que diz respeito à eficácia horizontal dos direitos fundamentais.

\section{A Vinculação dos Particulares a Direitos Fundamentais e sua Fundamentação no Direito Brasileiro}

$\mathrm{Na}$ Constituição da República Federativa do Brasil, não há, de maneira explícita, menção expressa à vinculação dos particulares a direitos fundamentais, diferentemente de outras Cartas Constitucionais. Destas, pode-se citar a Portuguesa (artigo 18), Russa (artigo 17) e Suíça (artigo 35). Porém, mesmo nestes países em que há expressa previsão da eficácia horizontal, ainda existem dúvidas sobre o alcance desta eficácia (ANDRADE, 2003, p. 223-244).

No Estado brasileiro, por não haver esta previsão explícita, é preciso que se interprete se, dentro de nossa Constituição, é possível inferir acerca da vinculação dos particulares a direitos fundamentais.

De vários dispositivos e construções teóricas, é possível se extrair a validade dos direitos 
fundamentais ante os particulares. Elas serão vistas a seguir.

\section{Supremacia da constituição}

Em nossa Carta Política, o princípio da supremacia da Constituição emana da noção de que a Constituição está no vértice do sistema jurídico nacional, conferindo validade ao mesmo, legitimando os poderes políticos na medida em que ela os reconhece e lhes atribui competências (DIREITO, 1997; SILVA, 2004, p. 45).

A supremacia da Constituição deriva-se, outrossim, do entendimento de que a Constituição Brasileira é rígida, vez que isso autoriza o controle de constitucionalidade, como adotado no Brasil (através do controle concentrado e, também, pelo difuso).

Por isso, sabendo que é o texto constitucional que atua como pedra angular de todo o resto do ordenamento jurídico e mais, sabendo que ele determina certas condutas no âmbito social, cultural e econômico, nada mais natural que pretender que suas ordens, também, vincularão os particulares, quando estes estiverem transacionando (STEINMETZ, 2004, p. 103-104).

\section{Dignidade da pessoa humana}

A dignidade da pessoa humana, fundamento da República, é um valor espiritual e moral, inerente ao homem, trazendo consigo a pretensão do respeito por parte das demais pessoas, constituindo-se o mínimo que o ordenamento jurídico deve assegurar. De acordo com Alexandre de Moraes (2005, p. 16), a dignidade humana como direito fundamental impõe que limitações aos direitos fundamentais ocorrerão somente em casos excepcionais, sempre, sem menosprezar a necessária estima que merecem os seres humanos.

A dignidade humana obriga a uma densificação valorativa que tenha em conta o seu amplo sentido normativo-constitucional e não uma ideia apriorística do que é o homem (SILVA, 2004, p. 105). Disso decorre que a ordem econômica tem como desiderato assegurar a todos a existência digna e a realização da justiça social, como proclamado no artigo 170 da Carta Política.

Bodin de Moraes entende que a Carta Magna conclama que nas relações privadas nas quais venha a ocorrer um conflito entre uma situação jurídica subjetiva existencial e uma patrimonial, a primeira deverá prevalecer, obedecendo ao corolário da dignidade humana como valor cardeal do sistema (MORAES, 2003, p. 105-148). Sabendo disto, é possível inferir-se que a dignidade da pessoa humana constitui o princípio que incorpora a exigência de justiça e ética, conferindo suporte axiológico ao ordenamento jurídico brasileiro, assumindo especial prioridade (PIOVESAN, 2009, p. 449-464).

Soromenho-Pires (2011, p. 157-186) aponta ainda que seria ilógico que os direitos fundamentais, erigidos a partir da noção da dignidade humana, situados na base de toda a sociedade, tenham sua eficácia limitada no que diz respeito aos indivíduos.

De tudo isso, sabendo que a dignidade da pessoa humana é fundamento da República Federativa do Brasil, é razoável pensar que a dignidade humana, valor que deve pautar todas as relações humanas, autorizaria que os direitos fundamentais sejam oponíveis, também, perante os particulares.

Aplicação imediata dos direitos e garantias fundamentais

$\mathrm{O}$ artigo $5^{\circ}, \S 1^{\circ}$ da Constituição estatui que as normas definidoras dos direitos e garantias fundamentais têm aplicação imediata. Decorre deste texto normativo que os poderes públicos estão imediatamente vinculados aos direitos fundamentais.

É possível afirmar que este dispositivo não autoriza a vinculação dos particulares a direitos fundamentais. Contudo, alguns direitos fundamentais já vinculam diretamente os particulares, como o direito à vida, à liberdade, à propriedade, entre outros diversos. Por isso, seria um disparate dizer que as normas de direito 
fundamental não vinculam, imediatamente, também, os particulares (STEINMETZ, 2004, p. 123).

Além disso, como sustenta Virgílio Afonso da Silva (2004), pelo fato da Constituição Brasileira, diferentemente de outras constituições (como a alemã) não ser expressa, no que diz respeito, à vinculação apenas dos entes públicos aos direitos fundamentais, o ônus argumentativo cabe àqueles que professam uma não vinculação dos particulares a direitos fundamentais.

Portanto, sem embargo de outros fundamentos, que, também poderiam ser aventados, estes são os alicerces no direito positivo brasileiro da vinculação dos particulares aos direitos fundamentais.

\section{Objeções às teorias}

Apesar de ser a teoria com mais ampla aceitação dentro da teoria constitucional europeia, a teoria da eficácia mediata também tem sido alvo de críticas. Acerca disso, podem ser apontadas as seguintes: crítica à utilização da Constituição Federal como sistema de valores, uma vez que existe quem aponte que esta utilização pode criar uma tirania dos direitos fundamentais, os quais passariam a determinar todas as relações jurídicas (SILVA, 2004, p. 102-103). O mesmo autor, também, aponta a insuficiência das cláusulas gerais como fonte de solução dos conflitos de direitos fundamentais e um eventual ferimento à autonomia do direito privado com a adoção da citada teoria da eficácia mediata (SILVA, 2004, p. 104-106).

Na mesma linha crítica, Steinmetz (2004, p. 164) assinala que o preenchimento das cláusulas gerais pelo conteúdo jusfundamental 'mistura' o conceito de direitos fundamentais, como princípios de Alexy, com o conceito de princípios, como cânones de interpretação.

Já no que diz respeito à tese da eficácia imediata, o constitucionalista português Canotilho (2003, p. 112) entende que, da tese da aplicação imediata, surgem mais problemas do que soluções.
Além disso, Virgílio Afonso Silva (2004) aponta outras objeções plausíveis à teoria da eficácia imediata, a qual seria grande risco à autonomia privada e 'borraria' as fronteiras entre o ramo do direito civil e do direito constitucional.

No que se refere à state action, Steinmetz (2004, p. 181), de maneira arguta, aponta que, apesar da engenhosidade da doutrina, a mesma não encontra eco no direito constitucional brasileiro, uma vez que nossa Constituição tem valores diametralmente opostos à Constituição estadunidense, a qual tem óbvia orientação liberal, ao contrário da nossa, a qual tem disposições liberais e outras não liberais.

Além disso, Silva, também, pontua que a jurisprudência estadunidense aplicadora da state action (especialmente julgados da Supreme Court) é casuística, acriteriosa, usando de artifícios argumentativos, quando deseja invalidar um ato de um particular ou quando deseja o contrário (SILVA, 2004, p. 128-130).

\section{Possíveis Soluções}

Em tese de doutorado sobre o tema, Steinmetz (2004) posiciona-se a favor da teoria da eficácia imediata, restringida esta, no caso concreto, pela aplicação do princípio da proporcionalidade. Já Sarmento (2003, 2004a), acerca da mesma problemática, entende como viável, também, a eficácia imediata, com a utilização de dois parâmetros: i) para o autor, deve existir nas relações entre particulares a incidência dos direitos fundamentais, caso exista grande assimetria entre as partes, ou seja, ocorrência de manifesta desigualdade material; ii) o segundo paâmetro de incidência dos direitos fundamentais nas relações entre particulares, para o autor, seria a verificação, no caso concreto, da existencialidade ou economicidadepatrimonialidade da relação jurídica em análise.

Em relação ao primeiro critério, Sarmento (2003, p. 273) assinala que, no momento em que o 
"ordenamento jurídico deixa livres o forte e o fraco, esta liberdade só se torna efetiva para o primeiro". No que diz respeito ao segundo critério, o autor baliza que a ponderação de interesses deve variar de acordo com a natureza da questão, ou seja, caso a relação prime pela existencialidade, a incidência de direitos fundamentais deverá ser mais intensa, enquanto que nas relações patrimoniais a incidência dos direitos fundamentais deverá ser refreada (SARMENTO, 2003, p. 279).

As posições dos dois autores são de interesse.

Todavia, em resenha que tratava de ambas as obras, Virgilio Afonso Silva (2005) apontou: 1) que o instituto da proporcionalidade, como formatado por Robert Alexy, não tem como intenção solucionar conflitos não estatais, sendo que a sub-regra da adequação não se coadunaria, de forma alguma, com as relações negociais; 2) que a desigualdade fática nem sempre é sinônimo de igualdade material e que tal solução ignoraria a desigualdade de forças presentes na relação jurídica negocial.

As contundentes críticas de Virgilio Afonso parecem ter parcial procedência, principalmente no que tange ao critério reputado por Steinmetz. Apesar disso, saliente-se que as 'precedências prima facie' criadas pelo autor têm elevado valor científico, servindo como substrato às conclusões do presente do trabalho.

De outro lado, no que diz respeito à crítica realizada contra a tese de Sarmento, esta parece ter menor grau de procedência.

Veja-se o exemplo utilizado pelo autor em sua crítica:

Aqueles que participam dos chamados reality shows, tão em voga no Brasil e no mundo, o fazem com base no exercício de sua autonomia da vontade. Esse exercício acarreta, sem dúvida, restrições de seus direitos fundamentais, especialmente ao de privacidade. A desigualdade material entre, por exemplo, a Rede Globo, uma das maiores empresas de comunicação do mundo, e os participantes de seu reality show é inegável. Isso não significa, contudo, que haja uma necessidade de intervir nessa relação para proteger direitos fundamentais restringidos: a desigualdade material não interfere, necessariamente, na autenticidade de vontades (SILVA, 2005, p.176).

Do caso apresentado como exemplo, é possível se retirar algumas considerações. Primeiro, é de rigor afirmar que em caso como este, por obviedade, o particular disposto a adentrar o reality show assinará um contrato regulamentando o uso de seu direito de personalidade à imagem. Portanto, pelo tempo em que o mesmo participar do programa, sua imagem será ‘propriedade’ da Rede Globo.

Se a consideração fosse apenas esta, a crítica de Virgilio Afonso seria no alvo, visto que, após a assinatura do citado contrato, caso o particular viesse a ingressar no Judiciário, pleiteando algo relacionado ao teor de sua imagem, pareceria que este particular estaria, apesar da grande desigualdade fática, equivocado.

Enquanto este artigo era elaborado buscou-se exaustivamente um exemplo concreto para refutar a crítica de Virgilio Afonso da Silva. Contudo, a vida real, tão mais rica em situações que a nossa imaginação, trouxe à lume interessante questão.

Durante o Big Brother Brasil 2012 (programa televisivo da Rede Globo), dois dos participantes (Daniel Echaniz e Monique Amin) envolveramse num episódio que repercutiu fortemente na mídia. Após uma festa promovida no programa, Daniel e Monique dormiram juntos, sendo possível observar uma movimentação intensa de Daniel Echaniz, enquanto Monique Amin, supostamente, estaria dormindo, o que acabou iniciando uma onda de reclamações de telespectadores acerca da possível ocorrência de estupro. Após a enorme repercussão do caso, Daniel Echaniz acabou sendo expulso do programa, tendo a Rede Globo alegado "comportamento inadequado" 12 .

Duas coisas devem ser salientadas, de acordo com as notícias que foram divulgadas: o participante foi comunicado de sua exclusão pela Rede Globo; após

\footnotetext{
${ }^{12}$ A narração dos fatos foi retirada de: (UOL, 17/jan./2012; UOL, 16/jan./2012; UOL, 16/jan./2012; SOUTO, 20/mar./2012).
} 
a exclusão do participante, à Polícia Civil do Estado de Rio Janeiro, a vítima negou ter sido estuprada. ${ }^{13}$

Neste caso, apesar da desigualdade fática entre as partes não ter, inicialmente, interferido na autenticidade das vontades (é, inclusive, elemento chave da própria configuração do programa), no decorrer da relação jurídica, a autenticidade modificou-se. Isto porque o participante foi excluído, sem sequer poder explicar-se ou, no mínimo, apresentar defesa. Neste caso, a violação a direitos fundamentais só existiu porque as partes estavam em situação absurdamente desigual, tendo a Rede Globo se utilizado de seu poder econômicocontratual, simbolizado pelo poder diretivo que a mesma detém no programa televisivo.

Percebe-se que, no caso em tela, utilizando-se do critério da desigualdade fática, e da teoria da eficácia mediata (com aplicação supletiva da imediata, uma vez que inexiste cláusula geral regulatória), o procedimento a ser utilizado seria: após a ocorrência do suposto estupro, a rede de televisão deveria ter comunicado o participante Daniel de que sua conduta era passível de exclusão, possibilitando a ele que se defendesse, com possibilidade de indicação de provas e outras possibilidades erigidas do devido processo legal. Após, os diretores da Rede decidiriam o destino do candidato. Salienta-se que, muito provavelmente, o resultado seria o mesmo: a exclusão de Daniel Echaniz. Contudo, a situação teria sido melhor para todos, uma vez que, ao excluído, teria sido possibilitado direito de defesa, vendo respeitados seus direitos fundamentais. A Rede Globo blindar-se-ia, inclusive, contra eventual processo judicial. Presumese, obviamente, que este 'processo particular' tivesse respeitado mínimas regras de contraditório e ampla defesa e, obviamente, com a possibilidade do acusado poder interferir em seu destino, ou seja, constatado que o devido processo particular não seria pro forma).
Dito isto, a utilização da desigualdade fática, como critério para aferição do grau de interferência dos direitos fundamentais nas relações privadas, parece, prima facie, ser interessante. Claro está que este critério deve ser utilizado da mesma maneira que os demais direitos fundamentais, ou seja, como um mandamento de otimização, criandose as relações de precedência condicionada. No exemplo mencionado, a precedência prima facie seria a da desigualdade fática, contudo, o caso concreto poderia ser similar ao exemplificado por Virgilio Afonso da Silva, sendo que a relação de precedência condicionada seria afastada após a devida argumentação.

Ou seja, no caso apresentado a comento, salvo melhores esclarecimentos por parte dos envolvidos, transparece a ocorrência de violação do devido processo legal na relação contratual entre Globo e Daniel Echaniz.

Outro critério adotado por Sarmento (2004a) é o da essencialidade da relação jurídica. Quanto mais econômico-patrimonial for a relação, menor deverá ser a incidência dos direitos fundamentais, sendo que, ao reverso, quanto mais existencial for a relação, maior deverá ser a vinculação dos particulares a direitos fundamentais. Parece pertinente, também, esta abordagem realizada pelo autor.

Portanto, apesar de Silva, Steinmetz e Sarmento não serem adeptos entusiasmados da teoria da eficácia mediata, do exposto neste trabalho, não há como fugir à sua aplicação no âmbito da dogmática dos direitos fundamentais brasileira.

A tese da eficácia mediata deve ser utilizada no Brasil, por não forçar uma invasão exagerada do direito privado pelo direito constitucional, como também por não ser demasiado afastada da possibilidade de vinculação dos particulares

\footnotetext{
${ }^{13}$ Não se trata aqui de fazer apologia às atitudes do rapaz eliminado, ou mesmo defendê-las. Aqui utiliza-se uma situação real rica em ramificações jurídicas ao tema aqui em comento para buscar-se uma solução dogmática diferenciada no âmbito da eficácia horizontal dos direitos fundamentais. A elucidação do crime (ou não) cabe à Polícia Civil, ao Ministério Público e ao Poder Judiciário do Rio de Janeiro.

Um outro ponto também deve ser levantado: o que acontecerá se Daniel Echaniz for (a título de exemplo) absolvido por não ter o fato constituído infração penal (CPP, 386, III).
} 
a direitos fundamentais. Ela é interessante por justamente estar no 'meio-termo'.

Importante ressaltar que, por se tratar de estudo realizado no seio da dogmática dos direitos fundamentais, a ponderação de interesses deve ser utilizada como instrumento da solução das tensões dos direitos fundamentais, já que, como visto anteriormente, os direitos fundamentais, em sua grande maioria, têm natureza de princípios, sendo que sua aplicação deve ser feita na maior medida do possível, dentro do caso concreto, ou seja, não são absolutos.

Neste diapasão, é possível se construir as seguintes prescrições hipotéticas, as quais deverão funcionar como parâmetros de incidência da vinculação dos particulares a direitos fundamentais:

1) Se, no caso concreto de restrição a direitos fundamentais numa relação entre particulares, existir mediação legislativa através de regras, o Magistrado deverá, prima facie, priorizar a solução àquele caso através da subsunção e não através da ponderação;

2) Se, no caso concreto de restrição a direitos fundamentais numa relação entre particulares, existir mediação legislativa através de cláusulas gerais, as mesmas deverão, prima facie, servir como 'porta de entrada' dos valores constitucionalmente consagrados, através de ponderação de bens realizada pelo Magistrado;

3) Se, no caso concreto de restrição a direitos fundamentais numa relação entre particulares, não existir mediação legislativa, o Magistrado deverá realizar a ponderação ou não, tendo em vista os dois critérios estabelecidos por Sarmento, qual sejam: a) em se tratando de relações eminentemente econômico-patrimoniais (caso no qual a aplicação horizontal dos direitos fundamentais deverá ser evitada, prima facie) ou de relação essencial (caso no qual a aplicação horizontal dos direitos fundamentais deverá ser fomentada, prima facie); b) se tratar de relação jurídica com eminente desigualdade fática (caso no qual a aplicação horizontal deverá ser fomentada, prima facie) ou se tratando de relação jurídica sinalagmática (caso no qual a aplicação horizontal deverá ser evitada, prima facie).

\section{Conclusão}

Diante da abordagem realizada, infere-se que os princípios jurídicos, para Robert Alexy (autor utilizado como substrato à pesquisa), não são mandamentos nucleares do sistema jurídico, mas, sim, mandamentos de otimização deste, sendo diferentes das regras, por serem passíveis de ponderação com os outros princípios que, a priori, poderiam parecer colidentes.

Viu-se, ademais, que os direitos fundamentais derivaram-se de lutas históricas dos cidadãos, sendo que estes, primariamente, possuíam a função de vincular o Estado a não realizar determinadas condutas, passando depois a obrigarem o ente estatal a prestar determinados serviços. Com a evolução da teoria constitucional e do constitucionalismo, além das mudanças nas relações de poder dentro da sociedade, a qual passou a ser uma sociedade de consumo de massa, as violações a direitos fundamentais passaram a não ser apenas oriundas do Estado, mas também, dos entes privados, como associações, sindicatos, corporações e dos próprios cidadãos. Disso, extraiu-se a necessidade de teorização acerca da possibilidade da vinculação dos particulares a direitos fundamentais. Neste diapasão, foi realizado aqui um estudo aprofundado sobre as vertentes da eficácia horizontal dos direitos fundamentais.

Ademais, observou-se que, apesar de no Brasil não haver determinação constitucional expressa acerca da vinculação dos particulares a direitos fundamentais, esta se extrai de diversas disposições constitucionais, como a dignidade da pessoa humana, a supremacia da Constituição e a aplicabilidade imediata dos direitos fundamentais, sem prejuízo de outras. 
Mais à frente, passou-se a um estudo das teorias da eficácia horizontal dos direitos fundamentais, detidamente da teoria da eficácia mediata, da eficácia imediata e da imputação do Estado. Ao final, após anotação das diversas vertentes, tomou-se posição, chegando-se a três proposições hipotéticodogmáticas.

\section{Referências}

ALEXY, R. Teoria dos direitos fundamentais. São Paulo: Malheiros, 2008.

. Teoria da argumentação jurídica: a teoria do discurso racional como teoria da justificação jurídica. São Paulo: Landy, 2001.

ANDRADE, J. C. V. Os direitos, liberdades e garantias no âmbito das relações entre particulares. In: SARLET, I. W. Constituição, direitos fundamentais e direito privado. Porto Alegre: Livraria do Advogado, 2003. p. 223-244.

APÓS suposto estupro, Daniel é expulso do "BBB12", diz jornal. F5 Folha Uol: televisão, São Paulo,16 jan. 2012. Disponível em: <http://f5.folha. uol.com.br/televisao/1035244-apos-supostoestupro-daniel-e-expulso-do-bbb12-diz-jornal. shtml>. Acesso em: 18 mar. 2012.

BARROSO, L. R. Neoconstitucionalismo e constitucionalização do direito. In: QUARESMA, R.; OLIVEIRA, M. L.; OLIVEIRA, F. M. R. Neoconstitucionalismo. Rio de Janeiro: Forense, 2009. p. 51-92.

BBB12: Monique negou estupro em depoimento à polícia. F5 Folha UOL: televisão, São Paulo, 17 jan. 2012. Disponível em: <http://f5.folha.uol. com.br/televisao/1035535-bbb12-monique-negouestupro-em-depoimento-a-policia.shtml>. Acesso em: 18mar. 2012.

BOBBIO, N. A era dos direitos. Rio de Janeiro: Elsevier, 2004.

BONAVIDES, P. Curso de direito constitucional. 18. ed. São Paulo: Malheiros, 2006.

. Curso de direito constitucional. 22. ed. São

Paulo: Malheiros, 2008.
BORELLI, R. S. O limite máximo da medida de segurança. Revista de Direito Público, Londrina, v. 6 , n. 3 p. 53-77, out./dez./2011. Disponível em: $\quad<$ http://www.uel.br/revistas/uel/index.php/ direitopub/article/view/8219/9069>. Acesso em: 23 jan. 2011.

BRAGA, P. S. Aplicação do devido processo legal nas relações privadas. Salvador: Juspodivm, 2008.

BUSTAMANTE, T. R. Princípios, regras e conflitos normativos: um modelo para a justificação de decisões contra legem a partir da teoria jurídica de Robert Alexy. Revista Pensar, Fortaleza, v. 15, n. 2, p. 603-627, 2010.

CANARIS, C.W. A influência dos direitos fundamentais sobre o direito privado na Alemanha. In: SARLET, I. W. Constituição, direitos fundamentais e direito privado. Porto Alegre: Livraria do Advogado, 2003. p. 223-244.

CANOTILHO, J. J. G. Civilização do direito constitucional ou constitucionalização do direito civil? A eficácia dos Direitos Fundamentais na ordem-jurídico civil no contexto do Direito pósmoderno. In: GRAU, E. R.; GUERRA FILHO, W. S. (Org.). Direito constitucional. Estudos em homenagem a Paulo Bonavides. São Paulo: Malheiros, 2003.

CASTRO, C. R. S. Extensão dos direitos e deveres fundamentais às relações privadas. In: ROCHA, J. C. C.; HENRIQUES FILHO, T. H. P.; CAZETTA, Ubiratan (Org.). Direitos humanos: desafios humanitários contemporâneos: 10 anos do estatuto dos refugiados: Lei n. 9474 de 22 de julho de 1997. Belo Horizonte: Del Rey, 2008, p. 133-152.

DANIEL é expulso do "BBB12" após "comportamento inadequado". UOLEntretenimento: televisão, São Paulo, 16 jan. 2012. Disponível em: $<$ http://televisao.uol.com.br/bbb/bbb12/noticias/ redacao/2012/01/16/daniel-e-expulso-do-bbb12apos-comportamento-inadequado.htm $>$. Acesso em: 18mar. 2012.

FERREIRA FILHO, M. G. GRINOVER, A. P.; FERRAZ, A. C. C. Liberdades públicas: parte geral. São Paulo: Saraiva, 1978.

DIMOULIS, D.; MARTINS, L. Teoria dos direitos fundamentais. São Paulo: Revista dos Tribunais, 2008. 
DIREITO, C. A. M. Breves notas sobre o primado da constituição. Breves notas sobre o primado da constituição. Revista de Direito Administrativo, Rio de Janeiro, n. 209, p. 19-41, jul. /set. 1997.

DWORKIN, R. Levando os direitos a sério. São Paulo: Martins Fontes, 2002.

GOMES, D. V. Os princípios no direito positivo na visão de Ricardo Guastini. Ambito Jurídico, Rio Grande, v. 73, fev. 2010. Disponível em: <http:// www.ambito-juridico.com.br/site/index.php?n link=revista_artigos_leitura\&artigo_id=7172>. Acesso em: 24 jan. 2012.

GRINOVER, A. P.; CINTRA, A. C. A.; DINAMARCO, C. R. Teoria geral do processo. 28. ed. São Paulo: Malheiros Ed., 2011.

GUASTINI, Ricardo. Variaciones sobre temas de Carlos Alchourrón y Eugenio Bulygin. Derrotabilidad, lagunas axiológicas e interpretación. Análisis Filosófico, v. 26, n. 2, p. 277-293, nov. 2006. Disponível em: <www.scielo.org.ar/pdf/ anafil/v26n2/v26n2a05.pdf $>$. Acesso em: 20 jan. 2012.

GUERRA FILHO, W. S. Processo constitucional $e$ direitos fundamentais. 3. ed. São Paulo: Celso Bastos, 2003.

MARETTI, L. M. B. A eficácia dos direitos fundamentais nas relações entre particulares. Revista de Direito Público, Londrina, v. 5, n. 3, p. 66-80, 2010. Disponível em: $<$ http://www.uel.br/revistas/ uel/index.php/direitopub/article/view/7552/6638>. Acesso em: 6 jul. 2011.

MARMELSTEIN, G. Curso de direitos fundamentais. São Paulo: Atlas, 2008.

MELLO, C. A. B. Curso de direito administrativo. 8. ed. São Paulo: Malheiros, 2002.

MORAES, A. Direito constitucional. 18. ed. São Paulo: Atlas, 2005.

MORAES, M. C. B. O conceito de dignidade humana: o substrato axiológico e conteúdo normativo. In: SARLET, I. W. Constituição, direitos fundamentais e direito privado. Porto Alegre: Livraria do Advogado, 2003. p. 105-148.

NEUNER, J. O código civil da alemanha (BGB) e a lei fundamental. In: SARLET, Ingo Wolfgang (Org.). Constituição, direitos fundamentais e direito privado. Porto Alegre: Livraria do Advogado, 2003. p. 247-271.

PEREIRA, J. R. G. Apontamentos sobre a aplicação das normas de direito fundamental nas relações jurídicas entre particulares . Rio de Janeiro: Renovar, 2003. p. 119-192.

PIOVESAN, F. Direitos humanos, o princípio da dignidade humana e a constituição brasileira de 1988. In: QUARESMA, R.; OLIVEIRA, M. L.; OLIVEIRA, F. M. R.. Neoconstitucionalismo. Rio de Janeiro: Forense, 2009. p. 449-464.

SARLET, I. W. A eficácia dos direitos fundamentais. 10. ed. Porto Alegre: Livraria do Advogado, 2009.

. A eficácia dos direitos fundamentais. 4. ed. Porto Alegre: Livraria do Advogado, 2004.

Neoconstitucionalismo e influência dos direitos fundamentais no direito privado: uma visão panorâmica sobre o caso brasileiro. In: QUARESMA, R.; OLIVEIRA, M. L. P.; OLIVEIRA, F. M. R. Neoconstitucionalismo. Rio de Janeiro: Forense, 2009. p. 587-614.

. (Org.). Constituição, direitos fundamentais e direito privado. Porto Alegre: Livraria do Advogado, 2003. p. 223-244.

SARMENTO, D. Direitos fundamentais e relações privadas. Rio de Janeiro: Lúmen Júris, 2004a.

.A vinculação dos particulares aos direitos fundamentais no direito comparado e no Brasil. In:BARROSO, L. R. (Org.). A nova interpretação constitucional: ponderação, direitos fundamentais e relações privadas. Rio de Janeiro: Renovar, 2004b. p. 193-284.

A normatividade da constituição e a constitucionalização do direito privado. Revista da EMERJ, Rio de Janeiro, v. 6, n. 23, p. 272-297, 2003.

SILVA, J. A. Curso de direito constitucional positivo. 23. ed. São Paulo: Malheiros, 2003.

SILVA, L. V. A. A constitucionalização do direito: os direitos fundamentais nas relações entre particulares. 2004. Tese (Livre Docência em Direito Constitucional) - Universidade de São Paulo, São Paulo.

Direitos fundamentais e relações entre 
particulares. Revista Direito GV, São Paulo, v. 1, n. 1, p. 173-180, maio 2005a.

- Interpretação constitucional e sincretismo metodológico. In: SILVA, V. A. (Org.) Interpretação constitucional. São Paulo: Malheiros, 2005b. p. 115143.

- O proporcional e o razoável. Revista dos Tribunais, São Paulo, ano 91, n. 798, p. 23-50, 2002.

. Princípios e regras: mitos e equívocos acerca de uma distinção. Revista Latino-Americana de Estudos Constitucionais, Fortaleza, v. 1, p. 607-630, 2003.

SOARES, M. A. S. Sistematização de princípios e regras constitucionais tendo em vista o princípio da publicidade e a propaganda dos órgãos públicos. Scientia Iuris/UEL. Departamento de Direito Público e Privado, Londrina, v. 9, p. 23-49, 2005.

SOROMENHO-PIRES, A. C. S. Intimidade, personalidade e a eficácia vertical e horizontal dos direitos fundamentais. Revista de Direito Constitucional e Internacional, São Paulo, v. 19, n. 75, p. 157-186, jan. /out. 2011.

SOUTO, L. Após arquivamento, mãe do ex- BBB Daniel espera retratação da imprensa. F5- Folha UOL: televisão. São Paulo, 20 mar. 2012. Disponível em: $\quad<$ http://f5.folha.uol.com.br/televisao/1064558apos-arquivamento-mae-do-ex-bbb-daniel-esperaretratacao-da-imprensa.shtml $>$. Acesso em 20: mar.2012.

STEINMETZ, W. A vinculação dos particulares a direitos fundamentais. São Paulo: Malheiros, 2004.

- Princípio da proporcionalidade e atos de autonomia privada. In: SILVA, V. A. (Org.) Interpretação constitucional. São Paulo: Malheiros, 2005. p. 11-53.

TEPEDINO, G. Crise das fontes normativas e técnica legislativa na parte geral do código civil de 2002. In: . (Org.). A parte geral do novo código civil. Rio

de Janeiro: Renovar, 2002.

UBILLOS, J. M. B.i En qué medida vinculan a los particulares los derechos fundamentales? In: SARLET, I. W. Constituição, direitos fundamentais e direito privado. Porto Alegre: Livraria do Advogado, 2003. p. 299-338.

VIEIRA, O. V. Direitos fundamentais: uma leitura da Recebido em:fev. 2012 jurisprudência do STF. São Paulo: Malheiros, 2006. 